\title{
Predators, environment and host characteristics influence the probability of infection by an invasive castrating parasite
}

\author{
Alyssa-Lois M. Gehman ${ }^{1} \cdot$ Jonathan H. Grabowski $^{2} \cdot$ A. Randall Hughes ${ }^{2}$. \\ David L. Kimbro ${ }^{2}$ Michael F. Piehler ${ }^{3} \cdot$ James E. Byers $^{1}$
}

Received: 11 September 2015 / Accepted: 29 September 2016 / Published online: 8 October 2016

(C) Springer-Verlag Berlin Heidelberg 2016

\begin{abstract}
Not all hosts, communities or environments are equally hospitable for parasites. Direct and indirect interactions between parasites and their predators, competitors and the environment can influence variability in host exposure, susceptibility and subsequent infection, and these influences may vary across spatial scales. To determine the relative influences of abiotic, biotic and host characteristics on probability of infection across both local and estuary scales, we surveyed the oyster reef-dwelling mud crab Eurypanopeus depressus and its parasite Loxothylacus panopaei, an invasive castrating rhizocephalan, in a hierarchical design across $>900 \mathrm{~km}$ of the southeastern USA. We quantified the density of hosts, predators of the parasite and host, the host's oyster reef habitat, and environmental variables that might affect the parasite either directly or indirectly on oyster reefs within 10 estuaries throughout this biogeographic range. Our analyses revealed that both between and within estuary-scale variation and host characteristics influenced L. panopaei prevalence. Several additional biotic and abiotic factors were positive predictors of infection, including predator abundance and the depth of
\end{abstract}

Communicated by Joel Trexler.

Electronic supplementary material The online version of this article (doi:10.1007/s00442-016-3744-9) contains supplementary material, which is available to authorized users.

Alyssa-Lois M. Gehman

alyssamina@gmail.com

1 Odum School of Ecology, University of Georgia, 140 E. Green St, 30602 Athens, GA, USA

2 Northeastern University, Nahant, MA 01908, USA

3 Institute of Marine Sciences, University of North Carolina, Morehead City, NC 28557, USA water inundation over reefs at high tide. We demonstrate that in addition to host characteristics, biotic and abiotic community-level variables both serve as large-scale indicators of parasite dynamics.

Keywords Parasite $\cdot$ Parasitic castrators $\cdot$ Latitudinal gradients $\cdot$ Infection probability $\cdot$ Crustacea

\section{Introduction}

Like most free-living organisms, parasites vary in abundance over space and time. Unlike free-living species though, parasites require the presence of a competent host, increasing the number of external drivers that can affect variability in their abundance patterns. Hosts might vary in abundance, distribution and susceptibility, all of which affect the parasite's distribution and abundance (Smith et al. 2007; Byers et al. 2008; Morse et al. 2012; Anderson et al. 2013; Satterfield et al. 2015). Furthermore, even when competent hosts occur, not all communities or environments that are inhabited by hosts are equally habitable for parasites, since direct and indirect interactions between parasites and their predators, competitors, and the environment can influence the probability of a host population being infected (Pennings and Callaway 1996; Ezenwa et al. 2007; Thieltges et al. 2009; Altman and Byers 2014). Here, we aimed to evaluate factors that can influence parasite colonization and establishment that may operate at different scales.

Biological community members can affect parasites either directly-during free-living life stages (Lafferty 2008; Johnson et al. 2010; Locke et al. 2014), or indirectly by influencing their hosts (Hudson et al. 1992; Wild et al. 2011). For example, predators can negatively 
impact a parasite through direct consumption of the freeliving infective stages (Grutter 2002; Mouritsen and Poulin 2003; Lafferty 2008; Kaplan et al. 2009; Johnson et al. 2010). Additionally, the 'healthy herd' hypothesis suggests that predators can keep infection rates relatively low by selectively feeding on infected hosts (Packer et al. 2003; Hatcher et al. 2006). Predators may be an important factor that either enhances or reduces a host population's probability of infection.

The abiotic environment may also affect variability in parasite distribution. Environmental drivers can create "refuge" habitat at environmental extremes, where the host is able to survive and the parasite cannot ( $\mathrm{Li}$ et al. 2010; Lei and Poulin 2011). For example, in marine systems low pH can reduce free-living parasite survival, resulting in lower parasite diversity and richness (Marcogliese and Cone 1996), and many parasites are more vulnerable than their hosts to low salinity (Li et al. 2010; Lei and Poulin 2011; Studer and Poulin 2012). In addition, host habitat complexity and water movement might impact parasite distributions. For example, increased water flow may increase host exposure to water-borne parasites and pathogens, potentially increasing parasite recruitment and infection.

Broad-scale studies on parasite prevalence can be challenging, as many parasites are cryptic and infection can be difficult to detect. However, rhizocephalan barnacles that parasitize crustaceans are abundant, and their externally visible reproductive organ, the externa, facilitates studies of rhizocephalan distributions across large geographic areas (Grosholz and Ruiz 1995; Alvarez et al. 2001; Chan et al. 2005; Sloan et al. 2010; Freeman et al. 2013; O'Shaughnessy et al. 2014). Surveys of rhizocephalans reveal that infection prevalence is variable between sites (Grosholz and Ruiz 1995; Alvarez et al. 2001; Chan et al. 2005; Sloan et al. 2010). It has been hypothesized that variability in host susceptibility to infection can drive spatial variation in infection prevalence; however, there is currently limited data to support this hypothesis (Kruse et al. 2011; Grosholz and Ruiz 1995; Sloan et al. 2010).

Loxothylacus panopaei is a castrating rhizocephalan barnacle parasite that infects the mud crab Eurypanopeus depressus, as well as several other mud crabs (Reinhard and Reischman 1958; Kruse et al. 2011). Eurypanopeus depressus is an abundant oyster reef-dwelling crab occurring in oyster reefs from the Gulf of Mexico to Massachusetts Bay. Loxothyacus panopaei overlaps much of this range, but is native to the Gulf of Mexico and introduced to the US Atlantic coast from Long Island, New York to Cape Canaveral, Florida (Kruse and Hare 2007; Kruse et al. 2011; Freeman et al. 2013; Eash-Loucks et al. 2014; O'Shaughnessy et al. 2014). There are three genetic lineages of this parasite (Kruse et al. 2011), and E. depressus is infected by the ER lineage, which was first documented in North Carolina in 1983 and in Georgia and northeastern Florida in 2004/2005 (Kruse and Hare 2007; Eash-Loucks et al. 2014). Along the Atlantic coast, E. depressus is consumed by several fish species, as well as Callinectes sapi$d u s$, the commercially important blue crab. Eurypanopeus depressus utilizes the oyster reefs as a refuge from these highly mobile predators (Meyer 1994; Hulathduwa et al. 2011). While this is a relatively new invasion, all estuaries in the study are within a geographic range where the parasite had been documented for at least 5 years prior to the study. Prevalence of L. panopaei infections in E. depressus is spatially variable (Hines et al. 1997), making the parasite an excellent candidate for evaluating the potential influence of biotic and abiotic variables on its abundance.

To determine whether abiotic or biotic variables contribute to the probability of infection by $L$. panopaei in its invaded range, we conducted a detailed observational study. We conducted the survey within a single week at replicate estuaries across $>900 \mathrm{~km}$ of the South Atlantic Bight. We collected a suite of community-level variables, including the density of hosts and the occurrence of predators of both the parasite and host. Additionally, we collected environmental variables that we hypothesized would affect oyster habitat, including oyster density and vertical relief of oyster beds. We evaluated whether environmental attributes, host demographics or predators of the host and parasite influence the probability of finding $E$. depressus infected with L. panopaei.

\section{Methods}

\section{Field survey}

We selected five oyster reefs at each of 10 estuaries from Florida to North Carolina, creating a hierarchically structured design (Fig. 1, Kimbro et al. 2014). Reefs were selected to limit certain influential variables. All reefs were intertidal, located on tidal creek banks near the mouth of an estuary, near Spartina alterniflora and had a summer salinity around $25 \mathrm{ppt}$ (Byers et al. 2015). We placed permanent markers on each reef in a $3 \mathrm{~m} \times 3 \mathrm{~m}$ intertidal sampling area to enable repeated measurements. We conducted invertebrate surveys at all sites during 7 to 13-August-2010. On each reef, a single $0.25 \mathrm{~m}^{2}$ quadrat was placed mid-reef, in the center of the markers. All oysters, dead shells and sediments to a depth of $10 \mathrm{~cm}$ were excavated from inside each quadrat. Samples were brought back to the lab, rinsed and sieved with a $1 \mathrm{~mm}$ mesh, and all infauna (i.e. invertebrates that live within the oyster reef) were placed first in $70 \%$ ethanol and then in $10 \%$ neutral buffered formalin for storage. All mud crabs were identified to species and examined under a dissecting scope for an externa, the 
Fig. 1 Map of the South Atlantic Bight indicating the average prevalence $( \pm \mathrm{SD})$ of L. panopaei infection in $E$. depressus across five reefs, sampled in each of 10 estuaries (for additional information see Byers et al. 2015). Sample sizes are shown in parenthesis, and are uneven between estuaries as collections were standardized by sampling area

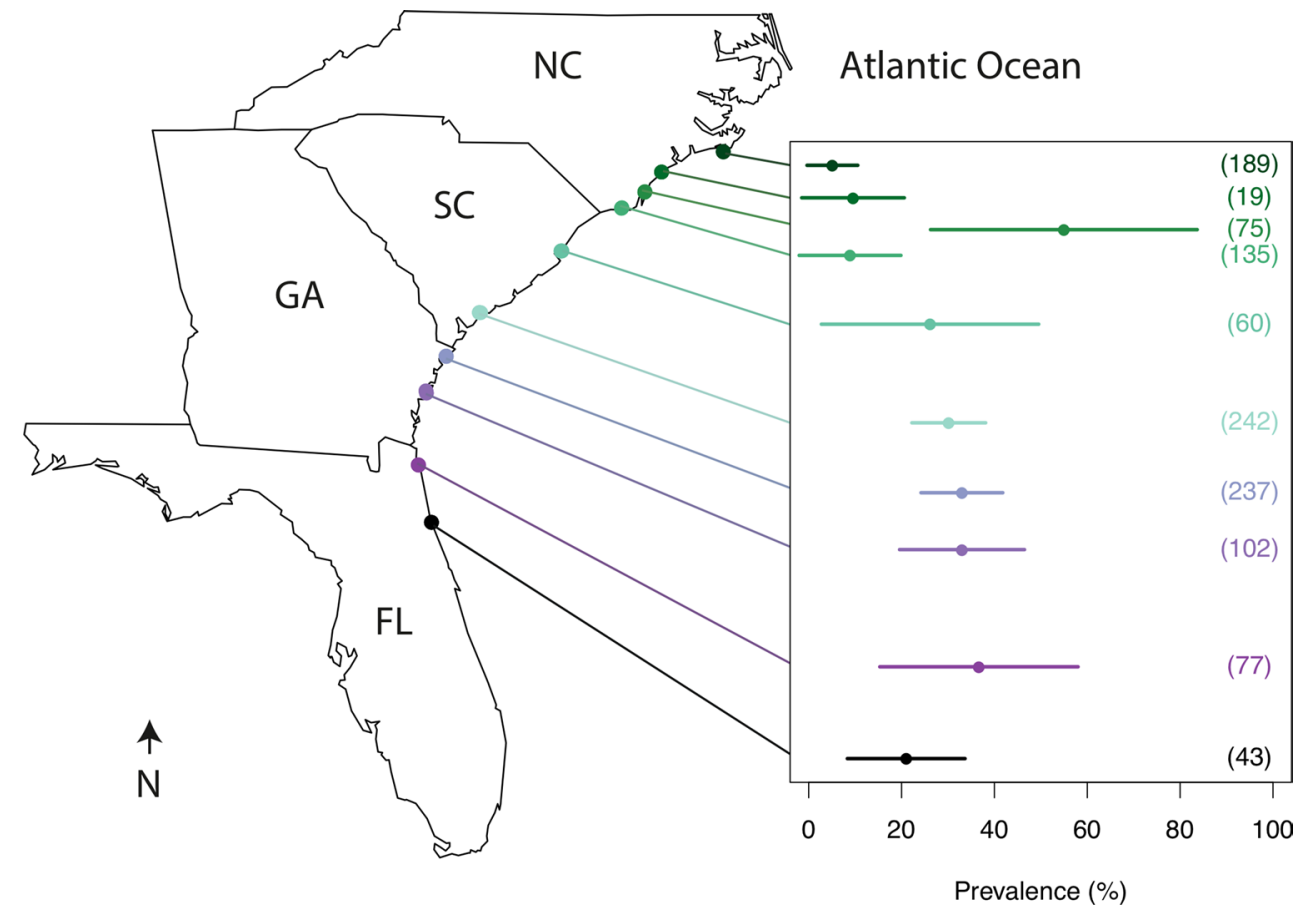

Other important predictor variables we quantified included Panopeus herbstii density, a large reef-dwelling mud crab competitor and predator of E. depressus, which we quantified $\mathrm{m}^{-2}$ during the infaunal invertebrate surveys. Crassostrea virginica recruitment, the number of live $C$. virginica $\mathrm{m}^{-2}$ and the physical characteristics of the oyster reef were previously quantified (Byers et al. 2015).

Temperature is often an important abiotic controlling factor that we wanted to capture in our analyses. Although temperature was measured at each estuary, this occurred only after the invertebrate survey in the fall of 2010, and as such was not explicitly included in this analysis. Temperature negatively correlates with latitude among the estuaries included in this study (Byers et al. 2015); so, the effect of temperature is implicitly accounted for in our inclusion of an estuary-level blocking factor (see below).

\section{Statistical analysis}

\section{Multicollinearity}

Statistical analysis was conducted in $\mathrm{R}$ ( $\mathrm{R}$ Development Core Team 2010). All variables collected were evaluated for multicollinearity (Online Resource 2). Any variables with a correlation coefficient greater then 0.70 were evaluated to determine biological relevance in relation to the response variable, and only the most relevant predictors were maintained in the model. There was a strong correlation between live oysters $\mathrm{m}^{-2}$ and oyster recruitment; so we kept only live oysters in our models. Water depth was have similar effects. 
correlated with several environmental variables, such as reef slope. As such, water depth was kept in the dataset and considered a proxy for general water movement over the reef.

\section{Probability of infection}

We evaluated the relationship between reef biotic and abiotic predictor variables and E. depressus infection probability by fitting a binomial generalized mixed effects model. The parasite response variable was infection status, i.e. the number of E. depressus with and without an L. panopaei externa ( 1 and 0$)$ within each quadrat on each reef. We included standardized host density, host size, number of Callinectes sapidus, Panopeus herbstii density, number of 'fish predators', number of 'other fish', vertical relief, and water depth as fixed variables, and infection status (0 or 1) as the response variable (Table 1; package lme4). We evaluated an exhaustive suite of models and used AICc for model selection to create a candidate set of models $(\triangle \mathrm{AICc}<2$; package MuMIn; Burnham and Anderson 2002). We accounted for the hierarchy of our design (10 estuaries with 5 reefs each) by including estuary as a random effect. Any unmeasured driver of variability between the estuaries, such as temperature, was captured in the estuary random term. We examined two additional models in comparative model runs, one that included reef as a random variable and one that included estuary and reef nested within estuary as random variables. When reef was included as a random variable (either nested or not), its inclusion raised the AICc (Online Resource 3 ) and did not change the significant variables maintained in the top models (Online Resource 4). Applying the philosophy of presenting the most parsimonious model, we did not include reef in the final model.

We standardized each of the predictor variables using the scale function, which subtracts the mean for each variable and then divides by the standard deviation. This standardization allowed for direct comparison of regression coefficients of each predictor variable. The relative variable importance (RVI) ranks all variables based on their frequency of occurrence in top models and was calculated from an exhaustive suite of models by summing the model weights over all models that included that variable (package MuMIn). To visualize the relationship between the fixed variables and infection status we used the function visreg (package visreg). We utilized several metrics of model fit, first evaluating the residuals of the model to the fitted model using plotresid in R to create a simulated quantile-quantile plot (package RVAideMemoire). For each of the top models, we calculated marginal and conditional pseudo- $\mathrm{R}^{2}$ values using the function r.squaredGLMM, evaluating the fit of fixed effects and the fixed + random effects model, respectively (package lme4; Nakagawa and Schielzeth 2013). To evaluate model accuracy at predicting infection status, we calculated area under the curve (AUC) for each of the top models using the function auc (package
Table 1 Descriptive statistics for biological and environmental variables measured across 50 oyster reefs sampled within 10 estuaries from Florida to North Carolina

\begin{tabular}{lllllll}
\hline Variable & Mean & SD & Min & Max & $N$ & Unit \\
\hline Infection prevalence & 26.19 & 20.61 & 0 & 100 & 1179 & $\%$ \\
Loxothylacus panopaei density & 25 & 27 & 0 & 100 & 50 & Infected crabs m $^{-2}$ \\
Eurypanopeus depressus density & 96 & 81 & 0 & 332 & 50 & Crabs m$^{-2}$ \\
Host size & 7.96 & 2.36 & 4.03 & 20.3 & 1179 & mm carapace width $^{2}$ \\
Panopeus herbstii density & 42 & 28 & 0 & 128 & 50 & Crabs m $^{-2}$ \\
Callinectes sapidus abundance & 1 & 2 & 0 & 7 & 50 & Crabs per trap \\
'Predatory fish' abundance & 7 & 9 & 0 & 36 & 50 & Fish per traps and gill \\
& & & & & & net \\
'Other fish' abundance & 5 & 4 & 0 & 14 & 50 & Fish per traps and gill \\
& & & & & & net \\
Crassostrea virginica density & 2468 & 2608 & 56 & 12048 & 50 & Oysters m \\
Vertical relief of oyster reef & 3.82 & 2.09 & 0.25 & 11.25 & 50 & cm \\
Avg water depth over reef at high tide & 0.56 & 0.16 & 0.21 & 0.79 & 10 & m \\
Salinity & 34.4 & 2.25 & 30.00 & 37.67 & 10 & ppt \\
\hline
\end{tabular}

Variables hypothesized to affect parasite prevalence were included, such as host density and size. Eurypanopeus depressus predators included Callinectes sapidus and 'predatory fish' a subset of fish confirmed to consume xanthid crabs based on gut content data (Online Resource 1). All other fish were included to evaluate for indirect effects. Panopeus herbstii is considered a competitor. Habitat variables included the number of Crossostrea virginica (live oysters), the vertical relief of the oyster reef and water depth over the reef. Salinity was standardized for polyhaline values as much as possible during oyster reef selection. Most variables were quantified at the reef level $(N=50)$, but water depth and salinity were quantified at the estuary level $(N=10)$ 
arm). In order to interpret the odds of finding an infected individual, we calculated the odds ratios (OR) by exponentiating the top model coefficients. The predictor variables are scaled, so the OR estimates the effect of one standard deviation change in the predictor variable.

\section{Parasite density}

To assess additional measures of parasite response, we evaluated parasite abundance, a parasite trait that is increasingly being recognized as important (Lagrue and Poulin 2015). We quantified parasite density as the number of $E$. depressus infected with $L$. panopaei $\mathrm{m}^{-2}$. Parasite density reflects the absolute abundance of parasites in an area, allowing evaluation of the relationship between resource (host) density and consumer (parasite) density (Lagrue and Poulin 2015). To evaluate whether E. depressus density had an effect on maximum parasite density, we ran a quantile regression (package quantreg; (Cade and Noon 2003; R Development Core Team 2010). We evaluated whether host density effected the maximum density of $L$. panopaei, using the upper (0.95) quantile (Cade and Noon 2003). XYpair bootstrapping was used to evaluate the fit of the model across each quantile.

\section{Results}

\section{Field survey}

Eurypanopeus depressus were present in all estuaries and were found at all but one of the 50 surveyed reefs, with a mean density of $96 \mathrm{crabs} \mathrm{m}^{-2}$ (Table 1). Loxothylacus panopaei were also found in all estuaries, but only at 40 of the 50 oyster reefs surveyed, with a mean density of 25 infected crabs $\mathrm{m}^{-2}$ and an infection prevalence across all samples of $26.18 \%$ (Table 1). Infection prevalence of L. panopaei varied within and between estuaries (Fig. 1). Five out of the 10 estuaries surveyed were first reports of $L$. panopaei infection, filling in previous gaps in the geographic range of the parasite. Biological and physical predictor variables varied across the geographic range sampled (Table 1), and patterns across estuaries are reported elsewhere (Kimbro et al. 2014; Byers et al. 2015).

\section{Probability of infection}

All models within the candidate set $(\triangle \mathrm{AICc}<2)$ were good fits to the data, with no patterns in the residuals and good levels of accuracy in prediction as calculated by AUC (Table 2). Fixed variables explained approximately $26 \%$ of the variance in the data, and the random variable estuary explained an additional $9 \%$ of the variance (as measured by the difference between the conditional and marginal pseudo $\mathrm{R}^{2}$, Table 2 ). Including estuary as a random variable improved the model fit substantially (based on residuals) and as such was included in all models.

The best-fit model for probability of infection included water depth, host size, 'fish predators', blue crabs and estuary as a random variable (Table 2; Fig. 2). Host size had the highest RVI and was included in all the candidate models (Table 2), with the odds of a crab being infected increasing $195 \%$ for every $2.36 \mathrm{~mm}$ increase in carapace width of a host (Table 2; Fig. 2). Water depth had the second highest RVI and was also included in all the candidate models, with the odds of a crab being infected increasing $105 \%$ for every $0.16 \mathrm{~m}$ increase in the depth of the water over the reef at high tide (Table 2; Fig. 2). 'Fish predator' presence had the third highest RVI and was included in all the candidate models, with the odds of a crab being infected increasing $42 \%$ for every 9 additional fish caught in the traps at that reef (Table 2; Fig. 2). The presence of C. sapidus was also included in all of the candidate models, with the probability of infection increasing $33 \%$ for every additional blue crab caught in the traps by the reef (Table 2; Fig. 2). Host density was included in 4 of the 5 candidate models but was not significant (Table 2; Fig. 2). Panopeus herbstii, 'other fish' and vertical relief were each included in one of the candidate models; however, these variables were non-significant when included, had low RVI and minimal B-coefficients, suggesting that they added very little to the interpretation. Among the candidate model set, the best-fit model had moderate support (weight $=0.33$ ) and all variables included had high RVI.

\section{Parasite density}

Host density was significantly and positively correlated with maximum densities of infected individuals across the range of host density evaluated in this study (95th quantile, $y=0.35 x+8.77, \beta=0.35, p>0.001$, Fig. 3).

\section{Discussion}

Our results show that host, environmental and biological community characteristics can explain variance in L. panopaei infection prevalence among estuaries across $>900 \mathrm{~km}$ of coastline. Host body size increases the probability of $L$. panopaei infection (Table 2; Fig. 2), and both water depth and predator abundance were associated with higher probability of $L$. panopaei infection (Table 2; Fig. 2). Localized variables that differed at the reef level were predominantly associated with variation in infection prevalence; however, the single estuary-level variable included-water depth (Table 1) - was a strong predictor of infection prevalence. 


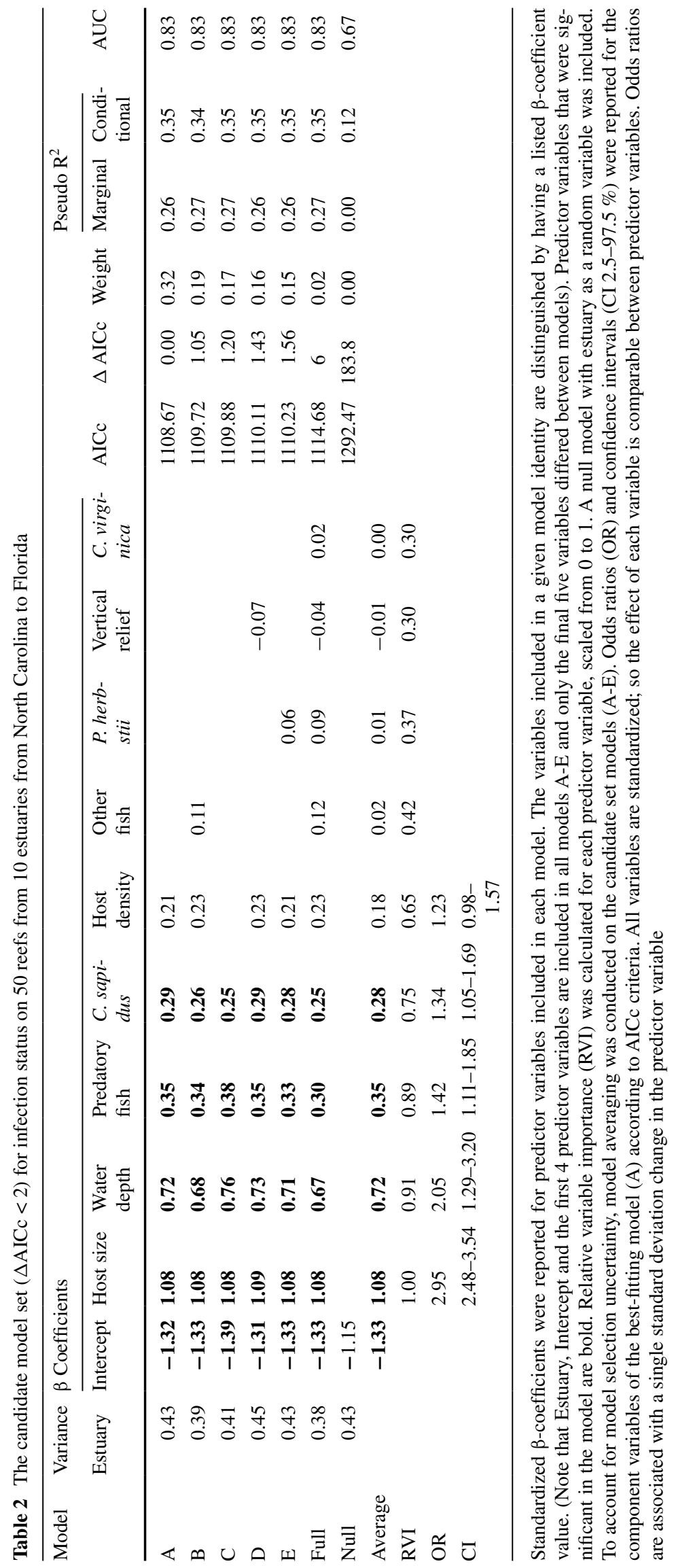



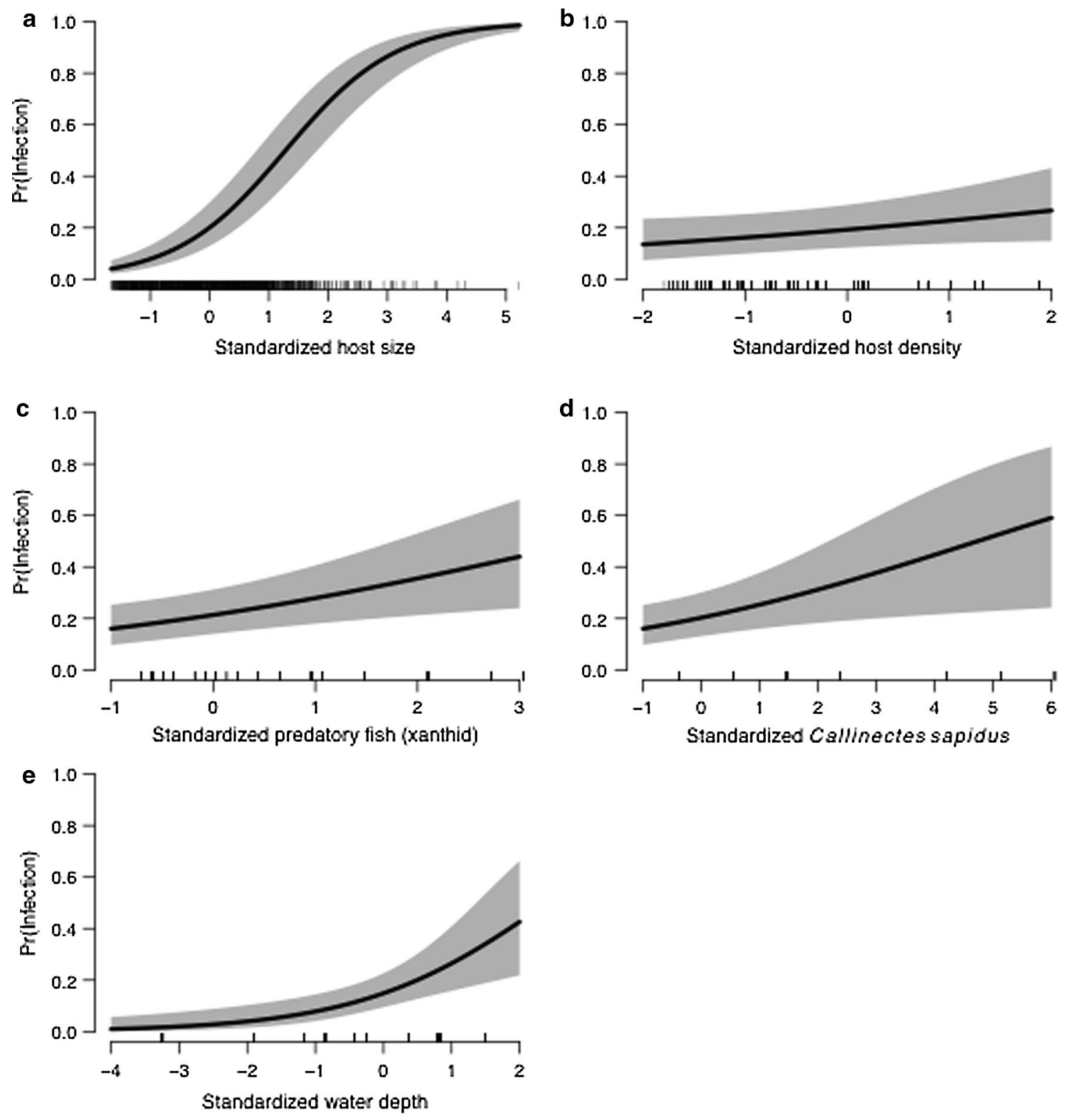

Fig. 2 Probability of infection as a function of each predictor variable included in the top model (model A in Table $2 ; n=1179$ ). Probability of infection was calculated based on an inverse logistic transformation applied to the log odds of infection. The $95 \%$ confidence intervals were calculated only considering the fixed effects (grey shading). Vertical hash marks along the $x$-axis indicate the spread of the data points used to fit the model. Differences in the number of hash marks between variables reflect the scale and resolution of each measurement; for example, water depth has fewer hash marks

Many of the influential variables were non-host factors. Increasingly, it is recognized that external (i.e., non-host) factors can influence parasite dynamics (Pennings and Callaway 1996; Thieltges et al. 2009; Altman and Byers 2014).

We found that predators were associated with increased L. panopaei infection prevalence. Predators can influence

because there was only one measurement per estuary. All predictor variables are standardized so that the effects of the variables are readily comparable among each other, with every unit change associated with a single standard deviation change in the predictor variable. a Standardized host size measure as carapace width $(\mathrm{mm})$, b Standardized host density measured as number of E. depressus $\mathrm{m}^{-2}$, c Standardized relative abundance of fish predators of small mud crabs (family Xanthidae), d Standardized relative abundance of Callinectes sapidus, e Standardized water depth over oyster reef (m)

host-parasite interactions, with evidence that direct predation can decrease infection by removing infected individuals (e.g., Hudson et al. 1992). Alternatively, consumption of an infected host might enhance transmission by spreading parasite propagules (e.g., Duffy et al. 2011). In addition to these consumptive pathways, predator avoidance behaviors can increase susceptibility of the host and thus 


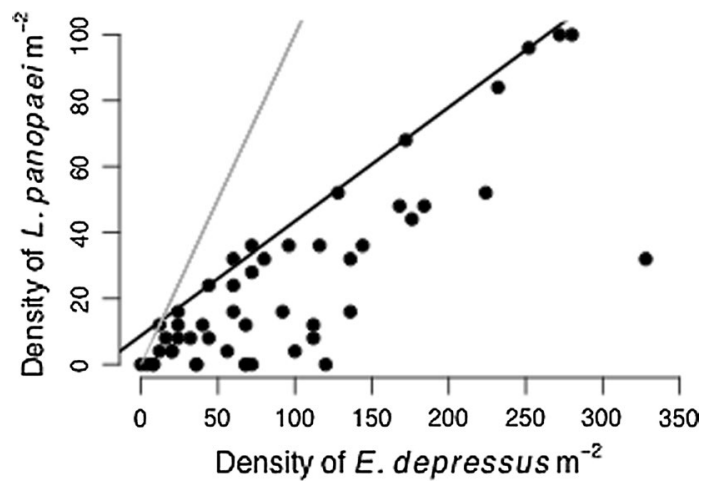

Fig. 3 The relationship of parasite (L. panopaei) density, as a subset of the total host $(E$. depressus $)$ density $(n=50)$. The grey line indicates the 1:1 line, which is the maximum possible density of $L$. panopaei if all crabs are infected with a single externa (100\% prevalence). The black solid line indicates the 0.95 quantile regression line, indicating the upper limit of infected individuals

enhance infection (e.g., Caceres et al. 2009). In our study, we found that the prevalence of infected E. depressus increased in the presence of host predators, including both predatory fish and blue crabs (Fig. 2c, d). When predators are highly mobile and the prey are less mobile, a positive association between predators and prey across large scales is likely (Sih 1982). If predators prefer infected, potentially more vulnerable, E. depressus, then a positive correlation between predators and infected hosts could be driven by predator aggregation near areas of higher infection prevalence within each estuary (Rose and Leggett 1990; Sih 2005; Wieters et al. 2008). Although mobile within the context of an oyster reef, $E$. depressus is likely confined to a given reef due to desiccation stress and high off-reef predation rates (Grant and McDonald 1979), thus reducing the chances that infected $E$. depressus can emigrate from high abundances of their mobile predators. Alternatively, positive correlations between infection and predator occurrence could indicate collinear responses to an underlying environmental variable.

Many marine parasites maintain a free-living larval stage, and as such may be influenced by the same recruitment dynamics as their free-living hosts. Water depth is associated with increased circulation and water volume moving over the reef, among a wide variety of other variables. In oyster reef communities, water depth is a positive predictor of multiple parasites, including $L$. panopaei infection prevalence examined here, and also Zaops ostreus, a pea crab parasite of oysters (Byers et al. 2013). In the case of the pea crab, parasite recruitment strongly mirrored host recruitment. However, that pairing may be less likely for L. panopaei and its host, as L. panopaei releases larvae throughout most of the year (Walker et al. 1992), and $E$. depressus only reproduces twice a year at most (McDonald
1982). The positive relationship between water depth and probability of infection (Fig. 2e) suggests that areas with more water moving over the reef are also experiencing higher recruitment of $L$. panopaei larvae.

As has been documented before (Alvarez et al. 1995; Hines et al. 1997; Poulin and Hamilton 1997), E. depressus size was a positive predictor of infection, with larger individuals more likely to be infected then smaller individuals (Fig. 2a). This could simply be because larger hosts are older and have had longer time to accrue infection. Or the positive relationship between host size and parasite size may indicate that smaller hosts do not have enough energy to sustain the energy demands of the parasite (Alvarez et al. 1995). Larger hosts can confer the additional benefit of increased energy available for parasite reproduction (Poulin 2007), and parasitic castration has often been associated with gigantism (Lafferty and Kuris 2009). Gigantism is unlikely in this host-parasite system, as the molt cycle (and thus growth) of E. depressus is halted following L. panopaei externa release and parasites in adult hosts release an externa after a single molt (O'Brien and Skinner 1990). However, there is some evidence that infected megalopae undergo several molt cycles before the parasite releases an externa (O’Brien and Skinner 1990; Alvarez 1993; Alvarez et al. 1995). Larger hosts produce substantially more parasite larvae (Alvarez 1993); thus, it is possible that L. panopaei infecting megalopae may be selecting larger hosts.

Theoretical models have long predicted that parasitoids and castrators should have a density-dependent response to host density (Hassell and May 1973; Hassell 1985; Murdoch et al. 2005) and be able to regulate their host populations (e.g. Kuris 1974; Negovetich and Esch 2008; Best et al. 2012). Parasite density often increases with host density (Blower and Roughgarden 1989; Lafferty 1993; Sonnenholzner et al. 2011; Lagrue and Poulin 2015); however, rhizocephalans have yet to be examined in this way. We found some evidence that probability of $L$. panopaei infection increased with $E$. depressus density; however, the relationship was not significant (Fig. 2b; Table 2). We found instead that the maximum density of $L$. panopaei is correlated with $E$. depressus density, and constrained to be approximately $35 \%$ of $E$. depressus density (i.e. $35 \%$ infection prevalence; Fig. 3). This apparent 'asymptote' in $L$. panopaei infection density may arise for several reasons. For example, L. panopaei can have devastating impacts on its host populations, with abrupt decreases in host populations correlated with the invasion of the parasite (Andrews 1980; Eash-Loucks et al. 2014). It is possible that the apparent $35 \%$ limit indicates the upper limit that the population can sustain without severe consequences for the host population.

This work demonstrates that although host characteristics are associated with parasite distribution, biological 
and physical variables can also influence parasite infection variability. Although all estuaries in our study could sustain parasites, variation in predation pressure and variables that may reflect parasite recruitment resulted in some areas having higher infection rates than others. Future work designed to evaluate the interactions among hosts, parasites and predators would illuminate a greater understanding of how these interactions structure ecological communities.

Acknowledgments Thanks to Caitlin Yeager, Tanya Rogers, Hanna Garland, Evan Pettis, Walt Rogers, Kaylyn Siporin, and Luke Dodd for their help collecting, storing and transporting samples. Thanks to Amanda Calfee for help processing samples and Tansy Moore for help with identification. Thanks to Chao Song and Alison Haupt for statistical input. UGA Shellfish Marine Extension Services provided space for sample processing. AMG was supported by a fellowship from the Wormsloe Institute for Environmental History. Funding was provided by the Odum School of Ecology to AMG. Funding was provided by the National Science Foundation to DLK and ARH (award \#1338372), to JHG (award \#1203859), to MFP (award \#0961929) and to JB (award \#0961853).

Author contribution statement JEB, DLK, ARH, JHG and MFP conceived and designed the survey, AMG, JEB, DLK, ARH, JHG and MFP conducted the survey, AMG processed the parasite samples, analyzed the data and wrote the manuscript. JEB, DLK, ARH, JHG and MFP provided editorial advice.

\section{Compliance with ethical standards}

Ethical approval All applicable institutional and/or national guidelines for the care and use of animals were followed.

Conflict of interest The authors declare that they have no conflict of interest.

\section{References}

Altman I, Byers J (2014) Large-scale spatial variation in parasite communities influenced by anthropogenic factors. Ecology 95:1876-1887. doi:10.1890/13-0509.1

Alvarez F (1993) The interaction between a parasitic barnacle, Loxothylacus panopaei (Cirripedia: Rhizocephala), and three of its crab host species (Brachura: Xanthidae) along the east coast of North America. Ph.D., University of Maryland, College Park, Maryland

Alvarez F, Hines AH, Reaka-Kudla ML (1995) The effects of parasitism by the barnacle Loxothylacus panopaei (Gissler) (Cirripedia, Rhizocephala) on growth and survival of the host crab Rhithropanopeus harrisii (Gould) (Brachyura, Xanthidae). J Exp Mar Biol Ecol 192:221-232. doi:10.1016/0022-0981(95)00068-3

Alvarez F, Campos E, Høeg J, O'Brien J (2001) Distribution and prevalence records of two parasitic barnacles (Crustacea: Cirripedia: Rhizocephala) from the west coast of North America. Bull Mar Sci 68:233-241

Anderson K, Ezenwa VO, Jolles AE (2013) Tick infestation patterns in free ranging African buffalo (Syncercus caffer): effects of host innate immunity and niche segregation among tick species. Int J Parasitol Parasites Wildl 2:1-9. doi:10.1016/j. ijppaw.2012.11.002
Andrews JD (1980) A review of introductions of exotic oysters and biological planning for new importations. Mar Fish Rev 42:1-11

Best A, Webb S, Antonovics J, Boots M (2012) Local transmission processes and disease-driven host extinctions. Theor Ecol 5:211217. doi:10.1007/s12080-011-0111-7

Blower S, Roughgarden J (1989) Parasites detect host spatial pattern and density: a field experimental analysis. Oecologia 78:138141. doi:10.1007/Bf00377209

Burnham KP, Anderson DR (2002) Model selection and multimodel inference: a practical information-theoretic approach. Springer Science + Business Media, New York

Byers J, Blakeslee A, Linder E, Cooper A, Maguire T (2008) Controls of spatial variation in the prevalence of trematode parasites infecting a marine snail. Ecology 89:439-451. doi:10.1890/06-1036.1

Byers JE, Rogers TL, Grabowski JH, Hughes AR, Piehler MF, Kimbro DL (2013) Host and parasite recruitment correlated at a regional scale. Oecologia 174:731-738. doi:10.1007/ s00442-013-2809-2

Byers JE, Grabowski JH, Piehler MF, Hughes AR, Weiskel HW, Malek JC, Kimbro DL (2015) Geographic variation in intertidal oyster reef properties and the influence of tidal prism. Limnol Oceanogr 60:1051-1063. doi:10.1002/lno.10073

Caceres CE, Knight CJ, Hall SR (2009) Predator-spreaders: predation can enhance parasite success in a planktonic host-parasite system. Ecology 90:2850-2858. doi:10.1890/08-2154.1

Cade BS, Noon BR (2003) A gentle introduction to quantile regression for ecologists. Front Ecol Environ 1:412-420. doi: $10.2307 / 3868138$

Chan BKK, Poon DYN, Walker G (2005) Distribution, adult morphology, and larval development of Sacculina sinensis (Cirripedia: Rhizocephala: Kentrogonida) in Hong Kong coastal waters. J Crust Biol 25:1-10. doi:10.1651/c-2495

Duffy MA, Housely JM, Penczykowski RM, Caceres CE, Hall SR (2011) Unhealthy herds: indirect effects of predators enhance two drivers of disease spread. Funct Ecol 25:945-953. doi:10.1111/j.1365-2435.2011.01872.x

Eash-Loucks WE, Kimball ME, Petrinec KM (2014) Long-term changes in an estuarine mud crab community: evaluating the impact of non-native species. J Crust Biol 34:731-738. doi:10.11 63/1937240X-00002287

Ezenwa VO, Milheim LE, Coffey MF, Godsey MS, King RJ, Guptill SC (2007) Land cover variation and West Nile virus prevalenence: patterns, processes and implications for disease control. Vector Borne Zoonotic Dis 7:173-180. doi:10.1089/ vbz.2006.0584

Freeman A, Blakslee A, Fowler A (2013) Range expansion of the rhizocephalan Loxothylacus panopaei (Gissler, 1884) in the northwest Atlantic. Aquat Invasions 8:347-353. doi:10.3391/ ai.2013.8.3.11

Grant J, McDonald J (1979) Desiccation tolerance of Eurypanopeus depressus (Smith)(Decapoda: Xanthidae) and the exploitation of microhabitat. Estuaries Coasts 2:172-177. doi:10.2307/1351731

Grosholz ED, Ruiz GM (1995) Does spatial heterogeneity and genetic variation in populations of the xanthid crab Rhithropanopeus harrisii (Gould) influence the prevalence of an introduced parasitic castrator? J Exp Mar Biol Ecol 187:129-145. doi:10.1016/0022-0981(94)00175-D

Grutter AS (2002) Cleaning symbioses from the parasites' perspective. Parasitology 124:S65-S81. doi:10.1017/S0031182002001488

Hassell MP (1985) Insect matural enemies as regulating factors. J Anim Ecol 54:323-334. doi:10.2307/4641

Hassell MP, May RM (1973) Stability in insect host-parasite models. J Anim Ecol 42:693-726. doi:10.2307/3133

Hatcher MJ, Dick JTA, Dunn AM (2006) How parasites affect interactions between competitors and predators. Ecol Lett 9:12531271. doi:10.1111/j.1461-0248.2006.00964.x 
Hines AH, Alvarez F, Reed SA (1997) Introduced and native populations of a marine parasitic castrator: variation in prevalence of the rhizocephalan Loxothylacus panopaei in xanthid crabs. Bull Mar Sci 61:197-214

Hudson PJ, Dobson AP, Newborn D (1992) Do parasites make prey vulnerable to predation? Red grouse and parasites. J Anim Ecol 61:681-692. doi:10.2307/5623

Hulathduwa YD, Stickle WB, Aronhime B, Brown KM (2011) Differences in refuge use are related to predation risk in estuarine crabs. J Shellfish Res 30:949-956. doi:10.2983/035.030.0337

Johnson PTJ, Dobson A, Lafferty KD, Marcogliese DJ, Memmott J, Orlofske SA, Poulin R, Thieltges DW (2010) When parasites become prey: ecological and epidemiological significance of eating parasites. Trends Ecol Evol 25:362-371. doi:10.1016/j. tree.2010.01.005

Kaplan AT, Rebhal S, Lafferty KD, Kuris AM (2009) Small estuarine fishes feed on large trematode cercariae: lab and field investigations. J Parasitol 95:477-480. doi:10.1645/GE-1737.1

Kimbro DL, Byers JE, Grabowski JH, Hughes AR, Piehler MF (2014) The biogeography of trophic cascades on US oyster reefs. Ecol Lett 17:845-854. doi:10.1111/ele.12293

Kruse I, Hare MP (2007) Genetic diversity and expanding nonindigenous range of the rhixocephalan Loxothylacus panpaei parasitizing mud crabs in the western North Atlantic. J Parasitol 93:575582. doi:10.1645/GE-888R.1

Kruse I, Hare MP, Hines AH (2011) Genetic relationships of the marine invasive crab parasite Loxothylacus panopaei: an analysis of DNA sequence variation, host specificity, and distributional range. Biol Invasions 1-15 doi:10.1007/s10530-011-0111-y

Kuris AM (1974) Trophic interactions - similarity of parasitic castrators to parasitoids. Q Rev Biol 49:129-148. doi:10.1086/408018

Lafferty KD (1993) Effects of parasitic castration on growth, reproduction and population-dynamics of the marine snail Cerithidea californica. Mar Ecol Prog Ser 96:229-237. doi:10.3354/ meps096229

Lafferty KD (2008) Ecosystem consequences of fish parasites. J Fish Biol 73:2083-2093. doi:10.1111/j.1095-8649.2008.02059.x

Lafferty KD, Kuris AM (2009) Parasitic castration: the evolution and ecology of body snatchers. Trends Parasitol 25:564-572. doi:10.1016/j.pt.2009.09.003

Lagrue C, Poulin R (2015) Bottom-up regulation of parasite population densities in freshwater ecosystems. Oikos 124:1639-1647. doi:10.1111/oik.02164

Lei F, Poulin R (2011) Effects of salinity on multiplication and transmission of an intertidal trematode parasite. Mar Biol 158:9951003. doi: 10.1007/s00227-011-1625-7

Li C, Shields JD, Miller TL, Small HJ, Pagenkopp KM, Reece KS (2010) Detection and quantification of the free-living stage of the parasitic dinoflagellate Hematodinium sp. in laboratory and environmental samples. Harmful Algae 9:515-521. doi:10.1016/j. hal.2010.04.001

Locke SA, Marcogliese DJ, Valtonen TE (2014) Vulnerability and diet breadth predict larval and adult parasite diversity in fish of the Bothnian Bay. Oecologia 174:253-262. doi:10.1007/ s00442-013-2757-x

Marcogliese D, Cone D (1996) On the distribution and abundance of eel parasites in Nova Scotia: influence of pH. J Parasitol 82:389 399. doi: $10.2307 / 3284074$

McDonald J (1982) Divergent life history patterns in co-occuring intertidal crabs Panopeus herbstii and Eurypanopeus depressus (Crustacea: Brachyura: Xanthidae). Mar Ecol Prog Ser 8:173-180

Meyer DL (1994) Habitat partitioning between the xanthid crabs Panopeus herbstii and Eurypanopeus depressus on intertidal oyster reefs (Crassostrea virginica) in southeastern North Carolina. Estuaries Coasts 17:674-679. doi:10.2307/1352415
Morse SS, Mazet JAK, Woolhouse M, Parrish CR, Carroll D, Karesh WB, Zambrana-Torrelio C, Lipkin WI, Daszak P (2012) Prediction and prevention of the next pandemic zoonosis. Lancet 380:9857. doi:10.1016/S0140-6736(12)61684-5

Mouritsen K, Poulin R (2003) The mud flat anemone-cockle association: mutualism in the intertidal zone? Oecologia 135:131-137. doi:10.1007/s00442-003-1183-x

Murdoch W, Briggs CJ, Swarbrick S (2005) Host suppression and stability in a parasitoid-host system: experimental demonstration. Science 309:610-613. doi:10.1126/science.1114426

Nakagawa S, Schielzeth H (2013) A general and simple method for obtaining R2 from generalized linear mixed-effects models. Methods Ecol Evol 4:133-142. doi:10.1111/j.2041-210x.2012.00261.x

Negovetich NJ, Esch GW (2008) Quantitative estimation of the cost of parasite casatration in a Helisoma anceps population using a matrix population model. J Parasitol 94:1022-1030. doi:10.1645/ GE-1310.1

O'Brien JJ, Skinner DM (1990) Overriding of the molt-inducing stimulus of multiple limb autotomy in the mud crab Rhithropanopeus harrisii by parasitization with a rhizocephalan. J Crust Biol 10:440-445. doi:10.2307/1548333

O'Shaughnessy KA, Harding JM, Burge EJ (2014) Ecological effects of the invasive parasite Loxothylacus panopaei on the flatback mud crab Eurypanopeus depressus with implications for estuarine communities. Bull Mar Sci 90:611-621. doi:10.5343/ bms.2013.1060

Packer C, Holt RD, Hudson PJ, Lafferty KD, Dobson AP (2003) Keeping the herds healthy and alert: implications of predator control for infectious disease. Ecol Lett 6:797-802. doi:10.1046/j.1461-0248.2003.00500.x

Pennings S, Callaway R (1996) Impact of a parasitic plant on the structure and dynamics of salt marsh vegetation. Ecology 77:1410-1419. doi:10.2307/2265538

Poulin R (2007) Evolutionary ecology of parasites. Princeton University Press, Princeton, New Jersey

Poulin R, Hamilton WJ (1997) Ecological correlates of body size and egg size in parasitic Ascothoracida and Rhizocephala (Crustacea). Acta Oecol 18:621-635. doi:10.1016/ S1146-609X(97)80047-1

R Development Core Team (2010) R: A languate and environment for statistical computing. R Foundation for Statistical Computing, Vienna

Reinhard EG, Reischman PG (1958) Variation in Loxothylacus panopaei (Gissler), a common sacculinid parasite of mud crabs, with the description of Loxothylacus perarmatus, n. sp. J Parasitol 44:93-97. doi:10.2307/3274835

Rose GA, Leggett WC (1990) The importance of scale to predatorprey spatial correlations: an example of Atlantic fishes. Ecology 71:33-43. doi:10.2307/1940245

Satterfield DA, Maerz JC, Altizer S (2015) Loss of migratory behavior increases infection risk for a butterfly host. Proc R Soc B 282:20141734. doi:10.1098/rspb.2014.1734

Sih A (1982) Optimal patch use: variation in selective pressure for efficient foraging. Am Nat 120:666-685. doi:10.1086/284019

Sih A (2005) Predator-prey space use as an emergent outcome of a behavioral response race. In: Barbosa P, Castellanos I (eds) Ecology of predator-prey interactions. Oxford University Press, New York, pp 240-255

Sloan LM, Anderson SV, Pernet B (2010) Kilometer-scale spatial variation in prevalence of the rhizocephalan Lernaeodiscus porcellanae on the porcelain crab Petrolisthes cabrilloi. J Crust Biol 30:159-166. doi:10.1651/09-3190.1

Smith NF, Ruiz GM, Reed SA (2007) Habitat and host specificity of trematode metacercariae in fiddler crabs from mangrove habitats in Florida. J Parasitol 93:999-1005. doi:10.1645/GE-1122R.1 
Sonnenholzner J, Lafferty K, Ladah L (2011) Food webs and fishing affect parasitism of the sea urchin Eucidaris galapagensis in the Galápagos. Ecology 92:2276-2284. doi:10.1890/11-0559.1

Studer A, Poulin R (2012) Effects of salinity on an intertidal host-parasite system: is the parasite more sensitive than its host? J Exp Mar Biol Ecol 412:110-116. doi:10.1016/j.jembe.2011.11.008

Thieltges DW, Fredensborg BL, Poulin R (2009) Geographical variation in metacercarial infection levels in marine invertebrate hosts: parasite species character versus local factors. Mar Biol 156:983-990. doi:10.1007/s00227-009-1142-0

Walker G, Clare A, Rittschof D, Mensching D (1992) Aspects of the life-cycle of Loxothylacus panopaei (Gissler), a sacculinid parasite of the mud crab Rhithropanopeus harrisii (Gould): a laboratory study. J Exp Mar Biol Ecol 157:181-193. doi:10.1016/0022-0981(92)90161-3

Wieters EA, Gaines SD, Navarrete SA, Blanchette CA, Menge BA (2008) Scales of dispersal and the biogeography of marine predator-prey interactions. Am Nat 171:405-417. doi:10.1086/527492

Wild MA, Hobbs NT, Graham MS, Miller MW (2011) The role of predation in disease control: a comparison of selective and nonselective removal on prion disease dynamics in deer. J Wildl Dis 47:75-93. doi:10.7589/0090-3558-47.1.78 